\title{
Optimalisasi Business Intelligence Pada Widuri Berbasis Mediawiki Dalam Monitoring Rekapitulasi Data
}

\author{
Optimization of Business Intelligence on Widuri of Mediawiki Based in \\ Recapitulation Monitoring Data
}

\author{
Khanna Tiara*1, Siti Nurhayati ${ }^{2}$, Novita Heriyani ${ }^{3}$ \\ ${ }^{1,2,3}$ Sistem Informasi STMIK Raharja \\ E-mail: *11khanna.tiara@raharja.info, ${ }^{2}$ siti.nurhayati@raharja.info, \\ ${ }^{3}$ novita.heriyani@raharja.info
}

\begin{abstract}
Abstrak
Seiring perkembangan zaman dan teknologi pada Perguruan Tinggi yang mengalami peningkatan sangat pesat. Peranan modal intelektual menjadi sangat penting dan strategis dalam pengelolaan program akademik untuk mencapai keunggulan kompetitif. Business Intelligence sebagai elemen penting dalam Perguruan Tinggi difungsikan untuk membantu manajerial mengelola modal intelektual dalam proses pengambilan keputusan guna meningkatkan kinerja Perguruan Tinggi. Penelitian ini bertujuan untuk mengimplementasikan Business Intelligence demi mendukung pengelolaan program akademik kearah yang lebih kompetitif melalui sistem perencanaan, pengukuran dan meningkatkan kinerja berbasis modal intelektual. Salah satu implementasi yang menggunakan sistem Business Intelligence dalam Perguruan Tinggi Raharja ialah website Widuri. Penggunaan Business Intelligence pada Widuri berbasis pada teknologi informasi yang bertujuan untuk mendesain, mengukur, mengelola dan mengembangkan modal intelektual, antara lain berupa pengetahuan, skill dan keahlian sumberdaya manusia Perguruan Tinggi Raharja. Penggunaan indikator kinerja Perguruan Tinggi Raharja dianalisis untuk memenuhi standar mutu Perguruan Tinggi yang kompetitif. Sehingga dengan penggunaan Business Intelligence pada Widuri mempermudah pengguna dan Admin mengetahui data secara akurat
\end{abstract}

Kata Kunci - Business Intelligence, Widuri, MediaWiki, Monitoring, Perguruan Tinggi

\begin{abstract}
As the development of the times and the technology at the College is currently undergoing a very rapid increase. The role of intellectual capital is becoming very important and strategic in the management of academic programs to achieve competitive advantage. Business Intelligence as an important element in the College functioned to help manage intellectual capital in the managerial decision-making process in order to improve the performance of colleges. This research aims to implement Business Intelligence to support the management of academic program towards a more competitive through a system of planning, measuring and improving performance-based intellectual capital. One implementation uses a system of Business Intelligence in the College website is Widuri Raharja. The use of Business Intelligence in information technology-based Thistle aims to design, measure, manage and develop intellectual capital, inter alia in the form of knowledge, skill and expertise of human resources College Raharja. The use of indicator performance College Raharja analyzed to meet quality standards at competitive Colleges. So with the use of Business Intelligence at Thistle make it easier users and Admins know data accurately.
\end{abstract}

Keywords - Business Intelligence, Widuri, MediaWiki, Monitoring, College. 


\section{PENDAHULUAN}

Penggunaan yang luas terhadap teknologi komputer dan jaringan yang telah membentuk suatu sistem elektronik besar yang menyimpan berbagai bisnis. Bagi sebuah organisasi hal ini sangat menguntungkan karena data yang diperlukan untuk mengambil keputusan sangat bergantung pada kelengkapan data yang dimiliki. Di lain pihak besarnya jumlah data ditambah kemungkinan tersebarnya lokasi penyimpanannya, akan lebih mempersulit pengaksesan data tersebut. Business Intelligence merupakan suatu kategori dari aplikasi dashboard yang bekerja secara real time akan memonitoring berbagai informasi yang dibutuhkan oleh suatu organisasi atau perusahaan dengan berbagai macam format seperti graphical gadgets, typically gauges, charts, indicators, dan color-coded maps. Secara ringkas, BI dapat diartikan sebagai pengetahuan yang didapatkan dari hasil analisis data yang diperoleh dari kegiatan suatu organisasi [1].

Akreditasi untuk institusi pendidikan tinggi dilakukan oleh Badan Akreditasi Nasional Perguruan Tinggi (BAN-PT). Maka kebutuhan akan data dan informasi tersebut bisa dipenuhi apabila Perguruan Tinggi telah memanfaatkan sistem informasi dan pengelolaan Business Intelligence sebagai sarana untuk melakukan sebuah keputusan dalam menginput data. Permasalahan yang sering terjadi pada Admin di Widuri saat ini adalah tidak efektif dalam mengelola data kunjungan pengguna pada Widuri. Dimana hal ini dapat menghambat pekerjaan Admin. Dengan menggunakan sistem Business Intelligence pada Widuri, Admin Widuri tidak lagi mengalami kesulitan saat melakukan input data kunjungan pengguna maupun berapa artikel yang memuat dalam Widuri. Karena dengan adanya sistem Business Intelligence pada Widuri dapat menghasilkan data yang akurt serta real time.

Penelitian ini akan membahas mengenai bagaimana cara kerja sistem Business Intelligence untuk mempermudah Admin Widuri dalam input data kunjungan pengguna. Maka diperlukannya sistem Business Intelligence, agar dapat memberikan kemudahan dan juga keamanan kepada pengguna Widuri.

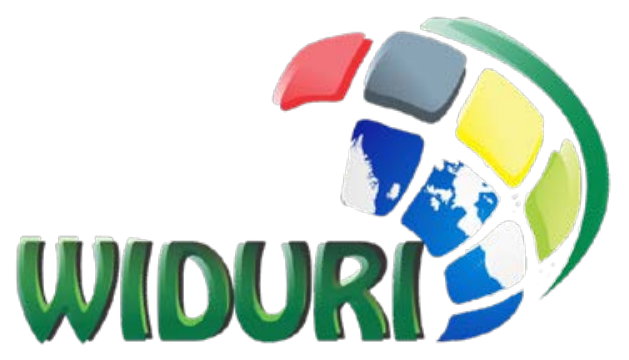

Gambar 1. Logo Widuri

Sumber: Filosofi Logo Widuri (2015: timur.ilearning.me)

Gambar 1 merupakan logo dari website Widuri yang merupakan salah satu sarana pada Perguruan Tinggi Raharja. Sebagai salah satu sarana dalam Perguruan Tinggi yang bergerak dalam bidang Teknologi Informasi, Widuri ikut serta berperan dalam sistem perkuliahan yang dijalankan di Perguruan Tinggi Raharja, salah satunya adalah sebagai alat bantu membuat suatu artikel ilmiah maupun CV untuk pribadi Raharja.

Widuri (Wiki iDu Raharja iLearning) merupakan sistem pelayanan informasi dengan menggunakan Wiki. Dimana pembaca dapat secara bebas mengakses, membaca artikel serta informasi didalamnya. Artikel yang ada di Widuri selalu dalam tahap penyempurnaan, karena informasi yang terdapat didalamnya selalu dikembangkan. Konsep Business Intelligence baru digunakan beberapa tahun yang lalu, hingga sekarang. Asosiasi ini digunakan di seluruh bidang yang berbeda dari data teknologi untuk pemodelan bisnis. Business Intelligence dapat mewakili wilayah yang luas dari aplikasi dan teknologi yang berguna untuk mengumpulkan, menyimpan, menganalisis dan menyediakan akses ke informasi untuk meningkatkan kualitas pemodelan proses bisnis [2]. 
Penggunaan sistem Business Intelligence berbasis pada teknologi informasi bertujuan untuk mendesain, mengukur, mengelola dan mengembangkan modal intelektual. Beberapa hal yang termasuk dalam modal intelektual antara lain berupa pengetahuan, skill dan keahlian sumberdaya manusia. Penggunaan indikator kinerja kunci Perguruan Tinggi dianalisis untuk memenuhi standar mutu Perguruan Tinggi yang kompetitif [3]. Business Intelligence (BI) merupakan salah satu bentuk implementasi yang mampu menjawab kebutuhan untuk menganalisis masalah-masalah dan pengambilan keputusan. Secara ringkas, BI dapat diartikan sebagai pengetahuan yang didapatkan dari hasil analisis data yang diperoleh dari kegiatan suatu organisasi [4].

Business Intelligence sebagai salah satu istilah dari sistem pengambilan keputusan yang dapat membantu manajemen dalam satu hal yang bersifat memprediksi. Perguruan tinggi membutuhkan desain infrastruktur untuk membuat pondasi dalam implementasi Business Intelligence yang akan diimplementasikan pada internet atau yang disebut $e$-business [5]. Fungsi umum dari Business Intelligence merupakan sebagai pengelola data, analisis, manajemen bisnis, perbandingan, dan analisis prediktif. Hal lain terkait Business Intelligence yang bertujuan untuk mendukung pengambilan keputusan bisnis menjadi lebih baik. Dengan demikian sistem Business Intelligence dapat disebut sebagai sistem penunjang keputusan [6].

Perkembangan bisnis dapat menghasilkan pertanyaan baru di beberapa perusahaan, bagaimana mengatur sebuah interkoneksi paling efektif antar aplikasi domain, penyimpanan data, serta teknologi metodologi analisa yang bertujuan untuk mengoptimalisasi kinerja bisnis. Business Intelligence menggabungkan dari beberapa data, analisis, metodologi, dan informasi baru dengan pengetahuan bisnis, dan target pengambilan keputusan [7]. Sebuah proses untuk melakukan ekstraksi data-data operasional perusahaan dan mengumpulkannya dalam sebuah data warehouse. Selama proses ekstraksi juga dapat dilakukan transformasi dengan menerapkan berbagai formula maupun validasi sehingga didapat data yang sesuai dengan kepentingan analisis bisnis. Selanjutnya data pada data warehouse diproses menggunakan berbagai analisis statistik dalam proses data mining sehingga didapat berbagai kecenderungan atau pattern dari data. Kedepannya trend BI akan digabungkan dengan AI (Artificial Intelligence) [8].

Teknologi terbaru seperti sistem BI telah dikembangkan untuk meningkatkan proses organisasi melalui penyimpanan data yang digunakan untuk menganalisis dan menginterpretasikan informasi. Informasi dalam jumlah besar perlu dirubah untuk menghasilkan sebuah pengetahuan dan menggunakannya sebagai cara dalam mengurangi dan mencegah kesalahan. Teknologi ini membantu Business Solution dan integrasi management sistem informasi yang terdiri dari teknik dan strategi dalam BI [9].

MediaWiki ialah sebuah perangkat lunak bebas berbasis server dengan menggunakan lisensi GNU General Public License (GPL). Selain itu MediaWiki merupakan perangkat lunak implementasi wiki yang sangat andal, terskalakan dan kaya fitur. Mediawiki menggunakan PHP untuk memproses dan menampilkan data yang tersimpan dalam basis data MySQL, dan dibuat secara khusus untuk Wikipedia dan proyek-proyek lainnya dari Yayasan Wikimedia. Sama halnya seperti Wikipedia yang menggunakan MediaWiki, website Widuri dari Perguruan Tinggi Raharja menggunakan perangkat lunak MediaWiki.

\section{METODE PENELITIAN}

Metode penelitian yang diterapkan pada penelitian ini menggunakan metode permodelan UML (Unifield Modeling Language) dan Literature Review. UML (Unifield Modeling Language) adalah 'bahasa' pemodelan untuk sistem atau perangkat lunak berorientasi pada objek. Pemodelan (modeling) sesungguhnya digunakan untuk menyederhanakan permasalahan-permasalahan yang kompleks sedemikian rupa sehingga lebih mudah dipelajari dan dipahami [10]. Pengumpulan data diperoleh dengan cara teknik observasi, wawancara, serta studi pustaka. Dimana observasi ini dilakukan monitoring secara langsung atas website Widuri secara rutin. Kemudian wawancara yang dilakukan dengan pengelola website yang membahas tentang peran kerja Business 
Intelligence secara keseluruhan. Hal tersebut dapat dijadikan bahan pertimbangan untuk pengambilan keputusan dalam rangka peningkatan website Widuri. Setelah diterapkannya beberapa metode diatas dicari suatu alternatif pemecahan masalah dengan implementasi atas alternatif pemecahan masalah yang telah dipilih.

Kemudian setelah dilakukannya tinjauan dari sepuluh literature review yang ada, telah banyak penelitian mengenai sistem menggunakan Business Intelligence untuk meningkatkan metode sistem. Dari beberapa metode yang diterapkan diatas dapat dicari suatu pemecahan masalah dengan implementasi yang telah dipilih. Karena sistem yang diterapkan oleh Perguruan Tinggi Raharja masih secara manual oleh karena itu penulis melakukan penelitian tentang Business Intelligence untuk meningkatkan fasilitas kampus pada website Widuri. Maka dari itu penulis membahas hal "Optimalisasi Business Intelligence Pada Widuri Berbasis MediaWiki Dalam Monitoring Rekapitulasi Data” agar dapat memudahkan Admin dalam mengetahui data Widuri.

\section{HASIL DAN PEMBAHASAN}

Data yang diambil yaitu data dari artikel yang dibuat oleh pengguna serta data pengguna yang terdaftar pada Widuri. Hal tersebut untuk melihat kecenderungan pengguna teraktif pada Widuri sekaligus melihat seberapa banyak suntingan artikel yang dilakukan pengguna.

Proses pemanfaatan Business Intelligence dilakukan karena data yang didapat masih belum bisa menghasilkan data secara akurat dan real. Proses ini melibatkan beberapa pihak khusunya Mahasiswa yang selalu mendapat tugas dari tiap-tiap Dosen untuk membuat artikel di Widuri. Mahasiswa atau pengguna mendapat tugas dari Dosen tersebut untuk membuat artikel di Widuri. Ketika mahasiswa telah membuat artikel seharusnya jumlah data artikel sehingga tidak akan menyulitkan admin untuk mengelola data tersebut.

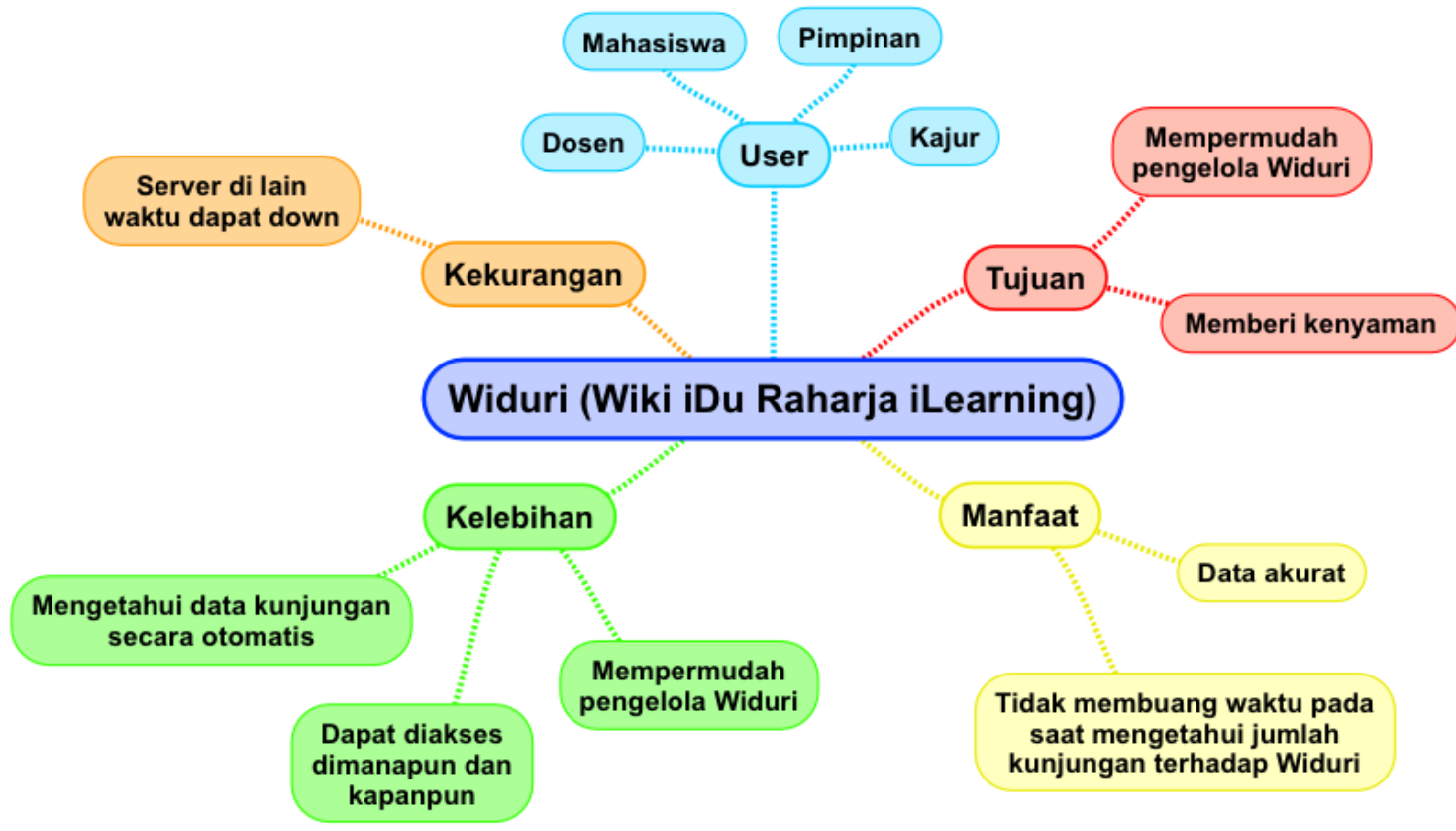

Gambar 2. Mindmap Widuri

Gambar 2 merupakan Mindmap Sistem Widuri, dapat dilihat kelebihan, kekurangan,dan manfaat bahkan tujuan yang terdapat di Mindmap Widuri tertera jelas.

Pengguna Widuri adalah dosen, kajur, maupun mahasiswa yang berada di Perguruan Tinggi Raharja yang dapat diakses dimanapun dan kapanpun. Dengan adanya Business 
Intelligence pada Widuri dapat memfilter pengunjung situs Widuri dan menghasilkan data akurat terkait jumlah artikel ilmipah maupun CV.

Flowchart ini menunjukan setiap terjadi mengenai Business Intelligence pada Widuri:

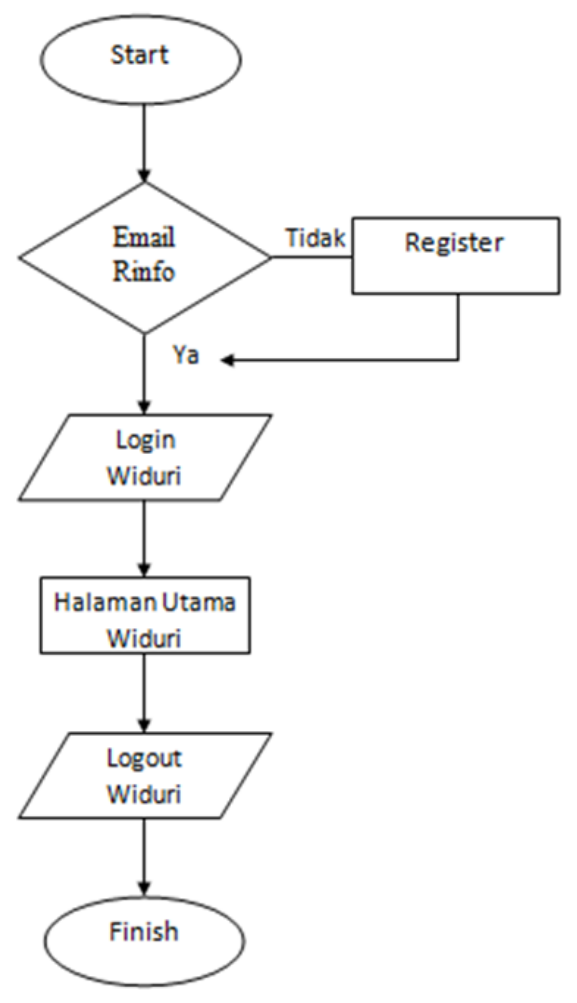

Gambar 3. Flowchart Diagram Business Intelligence Widuri

Gambar 3 Merupakan Flowchart sistem penghitungan pada Widuri, dapat dilihat bahwa penghitungan yang diterapkan oleh Widuri pada Pribadi Raharja saat login Widuri. Perhitungan Business Intelligence akan bekerja secara otomatis di Widuri.

Dari gambar di atas dapat dijabarkan bahwa hal yang pertama dilakukan oleh user adalah login dengan menggunakan email Rinfo di website Widuri. Jika pengguna belum memiliki e-mail Rinfo pengguna dapat melakukan register. Dan jika pengguna telah memiliki e-mail Rinfo pengguna dapat melakukan login pada Widuri. Setelah pengguna berhasil login, pengguna dapat langsung masuk ke dalam halaman utama dari Widuri. Maka dari login maupun yang registrasi pada Widuri dengan Business Intelligence terjadi proses penghitungan secara otomatis yang akan tampil pada halaman utama Widuri.

Pada Business Intelligence ini menggunakan perangkat MediaWiki dengan menggunakan bahasa program web semantics, dimana terdapat code program pemanggil data statistik di dalam Widuri, sehingga cara kerja optimalisasi Business Intelligence dapat temonitoring secara otomatis dan menghasilkan rekapitulasi data secara akurat. Berikut merupakan kodingannya:

$<$ !-- \#\#Whats Populer?\#\#\#-->

$<$ table style="border:3px solid \#AABBDD; background:\#E9F3FF; width:100\%; padding:10px; margintop:30px; border-collapse:collapse;" $><\mathrm{tr}><\mathrm{td}><\operatorname{div}$ style="float:left;margin-top:-25px;margin-left:25px;" $></$ div $><$ div style="font-size:150\%;border-bottom:1px solid \#AAAAAA" $><$ span style="fontsize:small;" $></$ span $>$ Tentang Widuri $</$ div $></$ td $></$ tr $><\operatorname{tr}><$ td $><$ p style="text-align:justify" $>$

Wiki iDu Raharja iLearning atau lebih dikenal "[[Widuri]]" setiap harinya selalu dikunjungi oleh Pribadi Raharja. Tidak berbeda dengan buku-buku pengetahuan atau buku pelajaran lainnya, Widuri memiliki sebuah halaman, dan saat ini sudah tercatat bahwa terdapat [[Istimewa:Statistik|\{\{NUMBEROFPAGES $\}\}]]$ halaman didalam Widuri ini. Terbukti pula bahwa 
Widuri sudah dikenal oleh hampir seluruh Pribadi Raharja. Mengapa tidak, pengguna Widuri saat ini tercatat sebanyak [[Istimewa:Statistik|\{\{NUMBEROFUSERS\}\}]] pengguna dan [[Istimewa:Statistik|\{\{NUMBEROFACTIVEUSERS $\}\}]$ ] pengguna aktif. Selain dapat membuat sebuah halaman, pengguna pun dapat saling berkontribusi pada halaman atau artikel yang ada (kecuali artikel yang sudah dikunci atau di protect), [[Istimewa:Statistik|\{\{NUMBEROFEDITS $\}\}]$ ] adalah angka atau jumlah suntingan saat ini. Mari kita tingkatkan kualitas Widuri, mulailah menjadi Pengguna Widuri dan berbagi ilmu dengan Widuri. $</ \mathrm{p}></ \mathrm{td}></$ tr $></$ table $>$

\&nbsp;

<table style="border:3px solid \#AABBDD; background:\#E9F3FF; width:100\%; padding:10px; bordercollapse:collapse;">

<span style="position:relative;right:-10px;top:10px" $></$ span $>$

$\{$ | style="width:100\%; margin-bottom:2px; clear:both;"

| class="fondlogo" style="background-repeat:no-repeat; width:100\%; border:1px solid \#A7D7F9; vertical-align:top; -moz-border-radius: 10px; -webkit-border-radius: 10px; border-radius:10px;" | \{l $\quad$ style="width:100\%; margin-bottom:2px; vertical-align:top; font-size:95\%; background:\#E9F3FF;align="justify" |-

Dari listing program di atas menjelaskan cara kerja sistem business intelligence pada Widuri yang bekerja secara otomatis. Yang memiliki fungsi sebagai input data mulai dari perhitungan berapa pengguna yang aktif di Widuri, perhitungan halaman keseluruhan di Widuri, dan perhitungan keseluruhan pengguna yang telah terdaftar di Widuri. Ketika pengguna melakukan login maupun membuat suatu halaman di Widuri, data langsung terekam di halaman utama Widuri. Business Intelligence telah di implementasikan pada Perguruan Tinggi Raharja sebagai sarana pengelola data kunjungan mahasiswa dan memperhitungkan jumlah halaman melalui website Widuri secara otomatis.

\subsection{Tampilan Sistem Business Intelegence pada Widuri}

Cara kerja sistem Business Intelligence akan secara otomatis tercatat perhitungan dari berapa halaman yang berada di Widuri, tercatat berapa banyak pengguna di Widuri, tercatat berapa pengguna yang aktif di Widuri, dan berapa suntingan artikel maupun CV yang berada di Widuri.

Tentang Widuri
Wiki iDu Raharja iLearning atau lebih dikenal "Widuri" setiap harinya selalu dikunjungi oleh
Pribadi Raharja. Tidak berbeda dengan buku-buku pengetahuan atau buku pelajaran lainnya,
Widuri memiliki sebuah halaman, dan saat ini sudah tercatat bahwa terdapat 7.544 halaman
didalam Widuri ini. Terbukti pula bahwa Widuri sudah dikenal oleh hampir seluruh Pribadi
Raharja. Mengapa tidak, pengguna Widuri saat ini tercatat sebanyak 2.391 pengguna dan
128 pengguna aktif. Selain dapat membuat sebuah halaman, pengguna pun dapat saling
berkontribusi pada halaman atau artikel yang ada (kecuali artikel yang sudah dikunci atau di
protect), 188.431 adalah angka atau jumlah suntingan saat ini. Mari kita tingkatkan kualitas
Widuri, mulailah menjadi Pengguna Widuri dan berbagi ilmu dengan Widuri.

Gambar 4. Tampilan Sistem Business Intelligence pada Widuri

Gambar 4 Menampilkan halaman utama Widuri, bisa di lihat coding yang sudah di berikan untuk halaman utama Widuri terdapat angka perhitungan otomatis pengguna terbanyak, halaman terbanyak, artikel terbanyak serta user yang aktif di dalam website Widuri. 


\subsection{Tampilan Login pada Widuri}

Tampilan login pada Widuri yang berisikan nama pengguna dan password untuk masuk ke dalam Widuri. Bagi User yang belum memiliki akun, bisa klik pada tombol Gabung widuri.

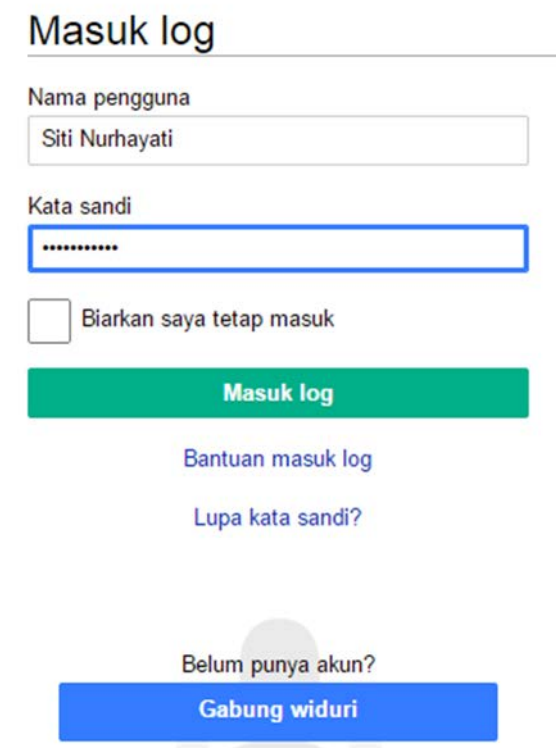

Gambar 5. Tampilan Login pada Widuri

Gambar 5 merupakan tampilan login user serta button gabung user ke Widuri, disini website Widuri belum menggunakan Single Sign On (SSO) atau masih manual.

\subsection{Tampilan CV Pengguna yang Masih Aktif}

$\mathrm{CV}$, artikel maupun pengguna yang masih aktif di Widuri keseluruhannya telah terdata dengan mefaatkan Business Intelligence. Agar data dalam CV pengguna selalu up to date maka pengguina bisa memanfaatkan fitur sunting.

\begin{tabular}{|c|c|c|c|c|c|c|c|}
\hline & halaman & pembicaraan & sunting & versi terdahulu & pindahkan & pantau & cek \\
\hline \multicolumn{3}{|c|}{ Biodata Siti Nurhayati } & \multicolumn{3}{|c|}{ Sunting halaman ini [alt-shift-e] } & & \\
\hline
\end{tabular}

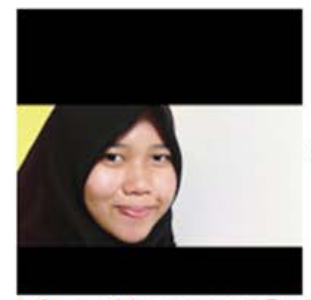

Siti Nurhayati kelahiran Lebak, 30 Desember 1995, panggilan akrabnya Nur. Saya anak pertama dar

Informasi konsentrasi Business Intelligence. Mengapa saya memilih jurusan SI ini? Karena ingin menguasai di berbagai bidang Multimedia, yang menggeluti seperti Film, Audio, Effect, Desain, dsb. Disisi lain karena saya memang hobi menggambar, Karyi memilih jurusan MAVIB, tapi saya putuskan untuk mencoba tantangan baru. Oke cukup sekian perkenalan diri saya. Semangat

Gambar 6. Tampilan CV Pengguna yang Masih Aktif

Gambar 6 merupakan tampilan CV yang telah dibuat oleh penggunaWiduri. Ketika pengguna telah selesai membuat CV maka BI yang di implementasikan pada widuri akan mendata secara otomatis. Sehingga hal tersebut akan memudahkan admin atau pengguna untuk mengetahui berapa banyak CV yang dibuat di Widuri. 
Citec Journal, Vol. 4, No. 1, November 2016 - Januari 2017

ISSN: 2460-4259

\subsection{Tampilan Sunting CV Pengguna Pada Widuri}

Tampilan sunting CV seperti yang terlihat pada gambar dibawah ini berisikan data diri pengguna Widuri. Setelah data CV atau artikel disunting, pengguna dapat menyimpan data tersebut, sehingga aktivitas suntung juga akan tercatat oleh Widuri.

\begin{tabular}{|c|c|c|c|c|c|c|}
\hline 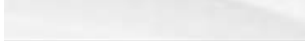 & halaman & pembicaraan & sunting & versi terdahulu & pindahkan & pantau \\
\hline
\end{tabular}

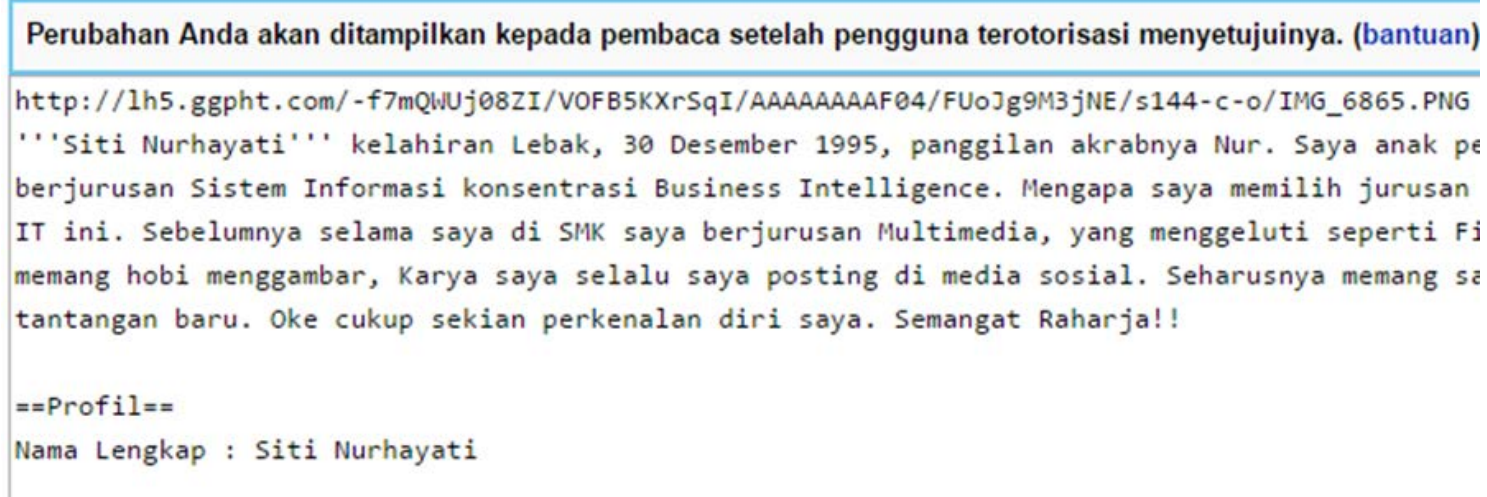

Gambar 7. Tampilan Sunting CV Pengguna pada Widuri

Gambar 7 Merupakan tampilan sunting CV pengguna yang terdapat pada Widuri yang merupakan tampilan menggunakan MediaWiki sama seperti Wikipedia. Dimana untuk menghasilkan suatu artikel di dalam Widuri menggunakan coding.

\subsection{Tampilan Update Sistem Business Inttelligence Jumlah Suntingan Pada Widuri}

Tampilan dibawah ini berisikan data statistik yang secara otomatis ter update pada Widuri, dimana sebelumnya jumlah data suntingan 188.431 dan setelah dilakukan sunting CV pengguna bertambah menjadi 188.433. Ini merupakan penerapan salah satu contoh Business Intelligence Widuri.

Tentang Widuri
Wiki iDu Raharja iLearning atau lebih dikenal "Widuri" setiap harinya selalu dikunjungi oleh
Pribadi Raharja. Tidak berbeda dengan buku-buku pengetahuan atau buku pelajaran lainnya,
Widuri memiliki sebuah halaman, dan saat ini sudah tercatat bahwa terdapat 7.544 halaman
didalam Widuri ini. Terbukti pula bahwa Widuri sudah dikenal oleh hampir seluruh Pribadi
Raharja. Mengapa tidak, pengguna Widuri saat ini tercatat sebanyak 2.391 pengguna dan
128 pengguna aktif. Selain dapat membuat sebuah halaman, pengguna pun dapat saling
berkontribusi pada halaman atau artikel yang ada (kecuali artikel yang sudah dikunci atau di
protect), 188.433 adalah angka atau jumlah suntingan saat ini. Mari kita tingkatkan kualitas
Widuri, mulailah menjadi Pengguna Widuri dan berbagi ilmu dengan Widuri.

Gambar 8. Tampilan Update Sistem Business Inttelligence Jumlah Suntingan Pada Widuri

Gambar 8 merupakan update sistem Business Intelligence jumlah suntingan pada Widuri, dari Gambar 4 terdapat perubahan data yang sebelumnya 188.431 sekarang menjadi 188.433. 


\section{KESIMPULAN}

Perkembangan Perguruan Tinggi yang kompetitif harus dapat mengelola sumber daya intelektual. Business Intelligence digunakan sebagai elemen penting dan strategis dalam proses pengambilan keputusan untuk membantu para Pimpinan, Manajer maupun Admin yang mengelola Widuri dalam meningkatkan kinerja Perguruan Tinggi. Business Intelligence berbasis pada teknologi informasi dan perangkat lunak yang digunakan untuk mengukur, mengelola serta mengembangkan pengetahuan sebagai modal intelektual. Untuk mencapai kinerja yang tinggi, perlu adanya kombinasi yang tepat dari berbagai sumberdaya, sistem, struktur organisasi untuk mengelola penggunaan penuh sumber daya, dan perhatian terhadap peluang dalam mencapai tujuan program bisnis akademik.

Kemudian dengan diterapkannya Business Intelligence pada website Widuri di Perguruan Tinggi Raharja, tentunya akan memberikan beberapa keuntungan dalam penerapannya, adapun keuntungan yang didapatkan dengan diterapkannya Statcounter ini adalah sebagai berikut:

1. Data dan informasi yang didapatkan dari Business Intelligence pada Widuri jauh lebih informatif dibandingan harus dilihat secara manual, namun dengan Business Intelligence proses monitoring aktivitas website Widuri Perguruan Tinggi Raharja dapat lebih mudah dilakukan.

2. Data dan informasi yang dihasilkan Business Intelligence pada Widuri dapat dijadikan bahan pertimbangan untuk pengembangan atau peningkatan website Widuri.

3. Proses sistem dalam Widuri dapat dilakukan dengan lebih baik dan terarah, serta proses dokumentasi berjalan dengan baik.

4. Hal ini dapat memudahkan Admin maupun Pribadi Raharja yang menggunakan website Widuri.

Kemudian selain kelebihan yang diberikan sistem Business Intelligence sebagai alat monitoring rekapitulasi data dalam website Widuri, juga masih terdapat sebuah kekurangan yaitu ketika banyak pengguna yang berkunjung di website server mengalami down server.

\section{SARAN}

Dari hasil penelitian masih dapat dikembangkan seperti penampilan Business Intelligence dalam menampilkan performa orang yang di belakang Widuri. Yang dimana bahwa artikel yang ada di Widuri harus diimplemtasikan ke tahap review artikel, dan dibutuhkan pula pemanfaatan sistem Business Intelligence di bagian review artikel Widuri. Sehingga dapat menghasilkan data yang akurat sama seperti pemanfaatan Business Intelligence dalam memonitoring website Widuri.

\section{DAFTAR PUSTAKA}

[1] Kusnawi, 2008, Implementasi Olap dan Reporting Services sebagai Bagian Proses Business Intelligence, Jurnal DASI, Vol 1, No 1.

[2] Nedelcu, B., 2013, Business Intelligence System, Database System Journal, Vol IV, No 4, hal 1-20.

[3] Mustafid, 2013, Sistem Business Intelligence untuk Mendukung Perguruan Tinggi yang Kompetitif, Jurnal Sistem Informasi Bisnis, Vol 6, No 1, hal 18-24,

[4] Adithama, S. P., Wisnubhadra. I., Sinaga, B. L., 2013, Analisis dan Desain Real-Time Business Intelligence untuk Subjek Kegiatan Akademik pada Universitas Menggunakan Change Data Capture, Seminar Nasional Teknologi Informasi dan Komunikasi, Yogyakarta, 9 Maret 2013. 
Citec Journal, Vol. 4, No. 1, November 2016 - Januari 2017

[5] Spits, W. H.L.H., 2008, Rancangan Infrastruktur E-Bisnis Business Intelligence pada Perguruan Tinggi, TELKOMNIKA, Vol 6, No 2, hal 115 - 124.

[6] Elena, C., 2013, Business Intelligence, Journal Scientific Papers, Vol 1, No 2.

[7] Horakova, M., Skalska, H., 2009, Business Intelligence and Implementation in a Small Enterprise, Journal of Systems Integration, No 2, hal 50-61

[8] Imelda, 2014, Business Intelligence, Majalah Ilmiah Unikom, No.1, Vol.11, hal 111-122.

[9] Mohammad Atwah Al-ma'aitah, 2013, The Role of Business Intelligence Tools in Decision Making Process, International Journal of Computer Applications, Vol.73, No. 13.

[10] Nugroho, A., 2010, Rekayasa Perangkat Lunak Berorientasi Objek dengan Metode USDP, Andi, Yogyakarta. 